Using Video Games to Support Pre-service Elementary Teachers Learning of Basic Physics Principles ${ }^{1}$

Janice Anderson $^{2}$, Michael Barnett ${ }^{3}$

${ }^{1}$ This work is supported in part through a Hewlett Packard Foundation - Teaching with Technology Program Grant\# 189660. We also would like to thank Kurt Squire at the University of Wisconsin for allowing us to use Supercharged!.

${ }^{2}$ Assistant Professor of Science Education University of North Carolina at Chapel Hill School of Education Peabody Hall 016A CB \#3500 Chapel Hill, NC 27599-3500, anderj1@unc.edu

${ }^{3}$ Associate Professor of Science Education and Technology, Department of Curriculum and Instruction, Teacher Education, and Special Education, Lynch School of Education, Boston College, barnetge@bc.edu 


\title{
Using Video Games to Support Pre-service Elementary Teachers Learning of Basic Physics Principles
}

\begin{abstract}
Abstract: The purpose of this work is to share our findings in using video gaming technology to facilitate the understanding of basic electromagnetism with preservice elementary teachers. To this end we explored the impact of using a game called Supercharged! on pre-service teachers' understanding of electromagnetic concepts compared to students who conducted a more traditional inquiry oriented investigation of the same concepts. This study was a part of a larger design experiment examining the pedagogical potential of Supercharged! The control group learned through a series of guided inquiry methods while the experimental group played Supercharged! during the laboratory sections of the science course. There was significant difference $F(2,134)=4.8, p<0.05, \eta^{2}=0.59$ between the control and experimental groups on the gains from pre-to-post assessment with an effect size of $d=0.72$. However, while students in the experimental group performed better than their control group peers, they rated their knowledge of the topic lower than the control group $\left(\mathrm{M}_{\text {post-control }}=3.0, \mathrm{M}_{\text {post-experiment }}=2.7\right)$, leading to further examination of their laboratory journals. Results of this study show that video games can lead to positive learning outcomes, as demonstrated by the increase in test scores from pre- to post-assessment. Additionally, this study also
\end{abstract}


suggests that a complementary approach, in which video games and hands-on activities are integrated, with each activity informing the other, could be a very powerful technique for supporting student scientific understanding. Further, our findings suggest that video game designers should embed meta-cognitive activities such as reflective opportunities into educational video games to provide scaffolds for students and to reinforce that they are engaged in an educational learning experience.

Keywords: electromagnetism, pre-service elementary teacher education, elementary science, video games, Supercharged!, electrostatics 
Running Head: Video Games, Physics, and Pre-service Elementary Teachers - NARST 2010 Philadelphia, PA 4

\author{
Using Video Games to Support Pre-service Elementary Teachers \\ Learning of Basic Physics Principles
}

\title{
INTRODUCTION
}

Computer/video games and other digital media such as virtual worlds are having a profound effect on both educational policy and practice in the United States and abroad (Dumbleton \& Kirriemuir, 2006; Mayo, 2009). In fact, a number of educators have argued that computer games can promote higher order thinking and learning through interaction and dialogue during the course of play (MacDonald \& Hannafin, 2003; Annetta, 2008; Mayo, 2007;2009). In support of these arguments, researchers have found that computer/video games can promote learning and engage students, helping them make sense of their worlds (Willamson \& Facer, 2004; Mayo, 2007;2009). Studies have demonstrated that video games can not only yield a potential increase in positive learning experiences, anywhere from seven to forty percent, over traditional classroom methods, but can also work to decrease the achievement gaps between students (Collar \& Scott, in press; Kettelhut, Dede, Clarke, \& Nelson, 2006; Kebritchi, Hirumi, \& Bai, 2008; Mayo, 2009; McClean, Saini-Eidukat, Schwert, Slator, \& White, 2001; Squire, Barnett, Grant \& Higginbotham, 2003). The National Science Foundation's Panel on Cyberlearning (2008) concluded that games and virtual environments can "transform STEM disciplines and K-12 education - both how technologies allow new ways of looking at and understanding content and how teachers can interact with students and their school assignments" (p.6). The potential of these games and virtual worlds to create learning experiences across multiple contexts by allowing students to interact within virtual laboratories, thereby creates new opportunities for interactive exchanges in a larger global classroom (NSF, 2008). However, 
despite the emerging research in their potential for harnessing learning, computer games are often met with trepidation by some teachers, parents, and students, who feel that games contribute little to learning, and are filled with distractions and inappropriate content (Dumbleton \& Kirriemuir, 2006; Egenfeldt-Nielsen, 2006; Engenfeldt-Nielson, 2004; Gros, 2003; Hostetter, 2003; Kirriemuir \& McFarlane, 2004; Prensky, 2004; Squire, 2004).

Today's students are often viewed as digital natives (Annetta, 2008; Oblinger, 2006; Prensky, 2001, 2006; Van Eck, 2006), who gather information from an array of resources, prefer inductive reasoning, have high visual literacy skills, and require fast and frequent interactions with content, all of which are supported by interaction with computers and aided or facilitated through games-based learning (Gee, 2003). As these digital environments become more prevalent within classroom contexts, teachers and other practitioners are interested in the positive benefits and learning outcomes that can emerge. However, these same educators have not recognized the paradigmatic shift that is implied by how students use these games within the classroom context through the ways in which student interrogate the worlds within the games (Annetta, 2008; de Freitas, 2006; Mayo, 2009; Shaffer, Squire, Halverson, \& Gee, 2004; Squire, 2003; Squire, 2006; Squire 2008). According to Squire (2006):

Games are an important site of a shift toward a culture of simulation, whereby digital technologies make it possible to construct, investigate and interrogate hypothetical worlds which are increasingly a part of how we both work and play..... (p.19)

The purpose of this study is to examine the learning outcomes when a $3 \mathrm{D}$ simulationcomputer game, Supercharged!, designed to support the teaching of electrostatics, was used to 
enhance pre-service teachers learning basic electromagnetic phenomena. Specifically, the primary driving questions for this research are:

1. What is the impact of learning with Supercharged on students' learning of electrostatic concepts?

2. What electromagnetic concepts were best learned through the use of the game as compared to traditional inquiry methods of learning similar concepts?

\section{BACKGROUND: PHYSICS CONCEPTS AND GAMES}

Many scientific domains deal with abstract and multi-dimensional phenomena that are often difficult for students to comprehend and apply. Mastery of abstract scientific concepts requires that students build flexible and testable mental models (Barnett, Keating, Barab, \& Hay, 2000; Redish, 1993). Frequently, however, students are asked to develop an accurate scientific mental model and to incorporate invisible factors and complex abstractions without real-life referents to aid their cognitive understanding (Chi, Feltovich, \& Glaser, 1991). For example, in the physics sub-field of electrostatics, students are expected to learn and understand electric fields and their associated representational formalisms that are three-dimensional, and abstract, with few real analogies to learners' everyday experience (Furio \& Guisasola, 1998). As a result, students have trouble conceptualizing the relationship of abstractions about electric fields to phenomenological dynamics (Chambers \& Andre, 1995). In addition, learners often have trouble understanding how an electric field would propel a test charge through the field if it were free to move (Dede, Salzman, Loftin, \& Sprague, 1999). This lack of understanding often occurs because students are unable to visualize the distribution of forces throughout a vector field. Additionally, students are unable to relate how that distribution of force translates into the 
motion of the test charge, or how to understand the concept of superimposed forces-at-a distance (Dede, et al., 1999). In short, research suggests, that students lack a qualitative understanding of the highlighted electric field concepts (Andre \& Ding, 1991; Bagno \& Eylon, 1997). It is believed that building such qualitative mental models lays the foundation for students' development of a more scientific, abstract understanding of electric field models (White \& Frederiksen, 1998).

To address this gap in student understanding, researchers (e.g. Erickson, 1993; Psotka, 1996; Bruckman \& Resnick, 1995; Gordon \& Pea, 1995) have been exploring how to use computational simulations (virtual reality) to assist students in visualizing basic electrostatic concepts (Dede, Salzman, \& Loftin, 1996). In reviewing the literature, we looked for specific instances of research-based games, which differ from virtual worlds. Games take advantage of goal directed advancement within game play, while 3D virtual worlds are more immersive, academic play-spaces that allow for inquiry and discovery learning (e.g. Barab, Sadler, Heiselt, Hickey, \& Zuiker, 2007; Barab, Ingram-Goble \& Warren, 2008; Kettlehut, Dede, Clarke, \& Nelson, 2006; Dede, Clarke, Kettlehut, \& Nelson, 2005) Supercharged! is a first person game that reflects the earlier work in the use of virtual reality to visualize charge of Dede and colleagues $(1996 ; 1999)$.

Many science educators advocate conceptual or qualitative physics, the notion that physics is best taught not through mathematical formulae, but rather through experiments, labs, demonstrations, and visualizations which help students to conceptually understand physical phenomena (diSessa, 2000; Forbus, 1997; Hewitt, 2002). Students bring to the classroom preconceived notions of science and scientific concepts that may not be entirely compatible with mainstream scientific thought, resulting in their difficulty with creating conceptual change 
(Brown \& Hammer, 2008; diSessa, 2008; diSessa, 2006; Duit, 2006). According to Brown and Hammer (2008), “as thinking moves on from the misconceptions paradigm”(p.141), it becomes necessary to reconsider these perspectives "within a dynamic systems" (p. 141) approach. Consistent with the Physics First (American Association of Physics Teachers, 2006) curricular movement, this perspective maintains that a deep, fundamental understanding of physics provides a solid basis for future science learning.

Digital technologies can immerse the learner in virtual spaces that not only incorporate scientific phenomena, but reflect the rules of physics. Simulated worlds can be programmed to behave according to Newtonian or Maxwellian rules (Dede et al., 1999). By representing these rules or concepts through simulations using digital gaming conventions, educators can potentially increase students' engagement while also fostering deeper learning; as learners engage in critical and recursive game play, they generate hypotheses about the game system to develop plans and strategies. They apply these strategies within game play, observing their results and adjusting their hypotheses about the game system (Cordova \& Lepper, 1996; Gee, 2003; Squire, 2003). The immersive nature of gaming environments provides experiences where students can draw upon their understanding of scientific concepts and use this intuitive knowledge developed in the context of simulated worlds to interpret real physics problems. By representing complex scientific content through tangible, experienced non-textually-mediated representations, simulated worlds may also engage reluctant learners in the study of science.

Advanced science students may have difficulty grasping non-intuitive, abstract physics concepts such as electromagnetism (Furio \& Guisasola, 1998). To help alleviate this problem, digital visualization technologies to assist physics teachers explain and teach conceptual physics. NASA award winning physicist John Belcher (2003) discussed animations in his teaching: 
Animation can give you access to levels of abstraction that you just can't get to with the math alone. It's particularly valuable for students who are trying to understand things at a conceptual level, because there is not too much intuition about electromagnetism... electromagnetism is largely hidden from their reality. Animations help my students visualize vector fields and other electromagnetic phenomena that they have a hard time conceptualizing from just the mathematics. When the students look at the topology of the moving field lines, they can understand intuitively many properties of the Forces transmitted by the fields (p. 2).

The aesthetic dimensions of these animations (See Figure 1), captured some of the physical beauty of electrostatics, making the basic ideas of the discipline of physics accessible to broader audiences (Belcher, Murray \& Zahn, 1999). As representations of electrostatic ideas, animations and visual depictions are not only tools for thinking about physics but objects that can engage, excite, and inspire learning.

[Insert Figure 1 about here]

Recently, the enhanced graphics capabilities of desktop computers coupled with their opens new opportunities for viewing and representing abstract scientific concepts in real time 3D. Only a few years ago, such simulations were only viewable within a virtual reality environment. In 1996, Dede and colleagues used computational simulations in virtual reality to assist students in visualizing basic electrostatic concepts, finding that 3D electrostatic simulations were valuable learning tools for teaching electrostatics. Dede and colleagues (1996) also reported that although learners found virtual reality applications engaging, they were frequently unsure as to how to interact with and learn from these virtual reality applications, 
when they anticipated a more game-like experience. The concept of Supercharged! emerged out of these findings and was developed by the MIT Games-to-Teach (2003) project. Pre-service Elementary Teacher Science Education

Supporting future elementary teachers in learning basic physics has proven to be challenging (e.g. Blumenfeld et al, 1991; Ginn \& Watters, 1995; McDermott \& Shaffer 2000; Schoon \& Boone, 1998). In fact, many science educators have recognized that both elementary and pre-service teachers struggle teaching physics topics conceptually (Forbus, 1997; diSessa, 2000). Elementary teachers have particular difficulty in comprehending physics concepts, such as the basics of electrostatics, which have very few real-life referents and incorporate invisible factors, forces operating at a distance, complex abstractions (Chi, et al., 1991).

According to Casperson and Linn (2006), students often have ideas and experiences about science topics that are disconnected. Research has shown that students will often hold these misconceptions around physics concepts such as the failure to realize that static cling and shocks from touching an object are examples of the same types of events. By using visualizations, simulations and game-like experiences, students are able to integrate these discrete ideas, making connections between macro and microscopic understandings (diSessa, 2000; Linn \& Eylon, 2006). Others (e.g. Miller, Lehman \& Koedinger ,1999; White \& Frederikse 1992; Guruswamy, Somers \& Husesey, 1997), have shown that students gain understanding of principles such as the forces between charged particles and conduction, when interacting with technology enhanced visualization models or games. Similar results were demonstrated by Squire, Barnett, Higginbotham and Grant (2003) in a study of electricity and magnetism with middle school students. We believe it is possible to use gaming structures such as fantasy, challenges, cooperation, or competition to create powerful learning tools, coupling the 
intrinsically rewarding aspects of games with the pedagogical power of simulations in order to teach complex conceptual physics topics to elementary pre-service teachers (e.g. Cordova \& Lepper, 1996). As learning scientists attempt to understand how learning occurs through game play, even more opportunities will exist to use emerging game technologies and design to engage students in meaningful learning (Games-to-Teach Team, 2003; Gee, 2003).

The purpose of this work is to share our findings in using video gaming technology to facilitate the understanding of basic electromagnetism of pre-service elementary teachers. To this end we explored the impact of using a game called Supercharged! on pre-service teacher understanding of electromagnetic concepts compared to students who conducted a more traditional inquiry oriented investigation of the same concepts.

\section{METHODS}

This study was a part of a larger design experiment examining the pedagogical potential of Supercharged! (Brown, 1992; Collins, 1990). We examine the classroom practices that emerged when Supercharged! was used to teach an electrostatics unit in a undergraduate physical science content course designed for future elementary teachers. In coordination with the course instructor and lab instructors, we identified three lab sections where Supercharged! was used, while three other lab sections conducted a series of inquiry-based investigations where the students explored the same electromagnetic concepts as the Supercharged! groups. The control group had 65 participants while the experimental (Supercharged!) group had 71 participants. Each group, both control and experimental, was expected to learn the same content. Both groups were mostly Caucasian $(>0.95)$ with five percent of the students falling into diverse populations. As such, the small sample size does not allow for an adequate examination 
of the impact of race/ethnicity in this study. Additionally, students were either in their first or second years of study. The control group participated in series of guided inquiry such as interactive lectures, experiments, observations, and demonstrations of the lab instructor's design. The primary experience of the experimental group was playing Supercharged! during their lab time (2 labs of 2 hours each). Both groups had access to the same supplemental materials and course lectures on the course website. These supplemental materials included links to the course lecture podcasts and various simulations from the web including the interaction simulations developed by the University of Colorado (http://phet.colorado.edu/index.php ), web resources such as Teacher's Domain (http://www.teachersdomain.org/collection/k12/sci.phys.maf.electric/) and content background reading for the lab. These materials were meant to provide supplemental resources for the students. The only required reading for the students were the lab documents which contained two-three pages of background content and the instructions for each lab.

Two lab instructors lead the groups; one lab instructor taught the experimental group while the other lab instructor taught the control group. Both of the lab instructors were graduate students studying geophysics and were not trained as teachers, nor did they have prior teaching experiences. The two lab instructors met with the course instructor prior to implementing the lab to discuss the structure of the two lab sections, the goals for the labs (learn same content), and to examine potential student challenges and misconceptions regarding the content. Given the physics background of the two student lab instructors, they were very comfortable with the content and the technology and as such did not have a preference as to which group to teach. The final decision was reached by a coin flip. Therefore, we believe that the confounding variable of having two different instructors, though still an issue, is a minimum one. 
The control group participated in a series of scientific investigations that were designed to help them learn the same concepts as their experimental group peers. These investigations included understanding the force of a magnetic field on a charged particle, the relationship between force on a test charge and distance, and the impact of electric fields on charges. Given that the students in the class were future elementary teachers, the control group investigated scientific concepts that they would typically see in their future elementary classrooms.

The first investigation required students to determine the impact of negative and positive charges on balloons and how charges transfer from one substance to another through the rubbing contact of glass and plastic rods with different materials such as wool, silk, and fur. For example, a student group would rub a balloon against a group member's hair to charge the balloon, and then test whether the balloon was attracted or repelled from the rods. During this activity the students had to pay careful attention to the distance between the rod and balloon and the impact of distances on the balloon. Afterwards, students were expected to charge up their balloon and hold it over torn shreds of paper; they evaluated the reaction of the balloon as it moved closer and closer to the paper. The students then followed up this investigation by evaluating the repulsive force between two balloons by bringing two balloons together and measuring the force of repulsion between them. In their final set of investigations, the control group students examined the structure of a magnetic field, the impact of a moving a magnet through a coiled wire by examining whether the speed at which the magnet moved impacted the magnitude of the current generated, and if a magnet would impact a stationary charged object such as their charged balloon.

Different from the traditional hands-on experiments conducted by the control group, the experimental group completed five levels of the Supercharged! game where they encountered 
the introduction of a new concept or increased difficulty at each level. For example, in level one the students were tasked with navigating their ship from one location to another while avoiding or using static charges in the space to help move their ship. By level five students were expected to navigate their ship through a maze that was filled with a magnetic fields and static electrostatic charges in order to exit the maze.

[ Insert Figure 2 about here]

\section{Data Sources}

This study used both quantitative and qualitative data sources to provide a holistic view of the laboratory experiences of both the control and experimental groups, identifying patterns of student understanding in the data collected in order to give insight into how students learn, process and understand concepts in electromagnetism. Prior to the intervention, a conceptual electromagnetism assessment consisting of seventeen questions was administered to both groups. The assessment included a space for the students to describe their logic for selecting/choosing a particular item response. The content exam was determined to have an internal consistency (Cronbach) of $\alpha=.72$ for the instrument which while on the low side is within acceptable range. The exam was also reviewed by two physicists to ensure that the questions were appropriate and that the questions were not confusing or misleading.

The students in both groups were also expected to maintain a laboratory notebook in addition to answering a particular set of conceptual electromagnetic questions as a part of their final lab report designed to probe their understanding of the specific electromagnetic concept. These laboratory notebooks were analyzed to identify students' ideas with respect to content and their perceptions regarding how the computer game helped or hindered their understanding of electricity and magnetism concepts. 
Student pairs were videotaped during each lab session. In total six groups were videotaped, three from the experimental labs and three from the control labs. In addition, a "roving" camera was used to move around the lab room, capturing "interesting" classroom moments. Finally, a researcher was always present recording their observations concerning student discussions, interactions with each other and/or the game, and students' frustrations and successes with the game. These were placed into a Filemaker Pro database which allowed for sorting for common themes and experiences. At the conclusion of the intervention both groups were given the conceptual electromagnetism assessment.

\section{Data Analysis}

The quantitative data was entered into SPSS and analyzed using ANOVA and ANCOVA techniques. Concurrently, the qualitative data was entered into a database and correlated with the appropriate question on the conceptual assessment. This analysis method allowed the researchers to cross-tabulate data to understand how students think about the physics concepts on both a macro and micro level. In order to develop a more nuanced understanding of how students' conceptions of electrostatics changed we purposively selected a subset of students' laboratory notebooks whose scores increased (3), decreased (3), and stayed about the same (3) for a more detailed analysis of their understanding.

The qualitative data was analyzed using naturalistic methods (Lincoln \& Guba, 1985) to examine how learning unfolded during the hands-on experiences of the control group and through game play of the experimental group. Researchers met informally between class sessions, and in three data analysis sessions following the intervention to analyze student data. Using the constant-comparative method (Glaser \& Strauss, 1967), researchers generated themes 
from the data, consulting video tapes and field notes to search for supporting and disconfirming evidence. Preliminary findings from both the quantitative and qualitative analysis are: (1) students in the game environment struggled to understand how magnetic fields interacted with charged particles; (2) both groups (control and experimental) learned electromagnetic content as was demonstrated through the assessments and lab notebooks, but the experimental group could describe how particles interact with one another better while the control group could better articulate what magnetic fields look like and how they change; and (3) students who used the game developed a conceptual understanding of the right-hand rule while students in the control group struggled to describe the forces that magnetic fields exert on charged particles. The following section will discuss these findings in greater detail.

\section{Results and Discussion}

Evaluating the quantitative assessment data, the experimental group generally outperformed the control group (see Table 1) on the conceptual electromagnetic questions. To measure the treatment effect the researchers calculated the effect size using a pooled standard deviation (mean square of the two standard deviations) which was $d=0.72$. According to Cohen (1988) this represents a large difference. 


\begin{tabular}{|l|l|l|l|l|l|l|l|l|}
\hline Group & $\mathrm{N}$ & $\mathrm{N}_{\mathrm{M}}$ & $\mathrm{N}_{\mathrm{F}}$ & Pre-Test & Std. & Post- & Std. & Change \\
& & & & & Dev & Test & Dev & \\
\hline Experimental & 71 & 30 & 41 & 6.2 & 1.70 & 9.4 & 1.20 & 3.2 \\
\hline Control & 65 & 20 & 45 & 5.9 & 1.72 & 8.3 & 1.27 & 2.8 \\
\hline
\end{tabular}

Table 1: Comparison of Means and Changes in Pre-Post Scores

A two-way ANOVA was also calculated with post-test scores as the dependent variable. Intervention (Experimental or Control) and Gender (Male or Female) were between-subjects variables. There was a significant difference between the experimental and control groups, $\mathrm{F}(2,134)=4.8, \mathrm{p}<0.05, \eta^{2}=0.59$ and no significant effect due to gender nor was there an effect on students' previous computer video game experience. However, an interesting finding was that despite the fact that the students in the experimental group performed better than their control group peers on the assessment they rated their knowledge of the topic lower than their control group peers $\left(\mathrm{M}_{\text {post-control }}=3.0, \mathrm{M}_{\text {post-experiment }}=2.7\right)$. This knowledge rating for both groups fell between the two categories of "I know a little but not comfortable about the topic" to "I'm pretty comfortable about the topic". There was not a statistically significant difference on the prescores for the self-perception question with the experimental group's mean at $M_{\text {pre-experiment }}=2.0$ and the control group's mean at $\mathrm{M}_{\text {pre-control }}=2.1$ ). Interestingly, the male students' scores also showed a larger change that the female students' scores, however the difference between the scores were not statistically significant. To understand these differences, the researchers examined the student writing in their laboratory notebooks, their open ended responses where the 
students justified their answer on the multiple-choice questions, and the nature of the discussions in each class. These results are presented in the following section.

\section{Content Understanding}

In general, we found that both student groups improved in their knowledge of basic electromagnetic concepts and improved their ability to articulate scientifically accurate explanations. What was most striking upon closer analysis was that students in the group who played the computer game Supercharged! could more accurately describe:

(1) the force of a magnetic field on a charged particle and the type of motion that a charged particle would experience upon entering a magnetic field;

(2) the relationship between force on a test charge and the distance between a test charge and another charge;

(3) the impact of electric fields on moving charges;

(4) students in the experimental group felt that they did not learn as much about electricity and magnetism when compared to their peers; and (5) the control group could construct more scientifically accurate explanations for the structure of a magnetic field around the impact of a magnetic field on a stationary charge in a magnetic field.

The significant difference between the control group and the experimental group who played Supercharged! are described and explained in more detail below. The analysis will also focus on the students' learning process and how they developed an understanding of electrostatics and magnetic concepts by playing Supercharged! The discussion will also explore the impact of video games on student conversations and learning. Within the discussion, we 
examine the control group data because it serves as a contrast or measure against which to compare the success and limitation of using educational video games in pre-service teacher classrooms. To this end, the discussion that follows is drawn primarily from the experimental group classrooms where Supercharged! was played with comparisons to the control group made to elucidate a particular challenge. This was done due to the significant difference found in the assessments of the control and experimental groups.

\section{$\underline{\text { Discussion }}$}

Assertion 1: Game Play allowed students to "be a charge" and experience forces

The primary goal of Supercharged! is for a player/players to change the charge of their "ship" in order to maneuver through a maze, under the specific conditions of the field of play. For example, if a player decides to move away from and pass a positive stationary charge sitting in space near them to progress through the maze, the player would simply change the charge of their ship to a positive charge. The resulting repulsive force between the two objects would move the ship away from the stationary charge. This would allow the player to continue to move through the maze. Below is an excerpt from a group who was trying to navigate toward the exit of the maze in level two of the game:

Student 1: There is the exit. So we need to go that way [pointing toward the screen]

Student 2: Ok, so this here is a positive charge right...

Student 1: I think so, look at its lines [the object has electric field lines leaving the charge which represented a positive charge]

Student 1: So we need to change to positive and probably a lot of positive charge so we can get through that magnetic field... 
Student 2: Ok [student 1 increases the charge on their ship to +5 , and the ship starts to move away quickly]. Oh, no! Look there is a negative charge that we are going to crash into it and get stuck!

Student 1: Quick change the charge to negative before we get too close - perhaps we can just graze it and use the force to push that way [pointing to the exit].

Student 2: What the.... What are we doing? We are going in a circle!?

[Insert Figure 3 about here]

While the students were engaged in a discussion about how to change the charge on their ship, the instructor walked over to the group and inquired about how they were progressing in the game. The students admitted they were perplexed and could not figure out how to maneuver their ship through the charged forces and out of the maze. The instructor engaged with the students, asking them about what steps they had already taken in the maze. The students admitted that they used static charge forces to push and pull their way toward the exit, but they also became trapped in a loop and were forced to go in circles. In response, the instructor asked them why their ship might have been caught and what specifically was happening. The first student guessed that there were a number of charges, both positive and negative, in the area of the maze where they were located. The student offered the following explanation:

See if we are here [point to the screen] then if there are a series of alternative positive and negative charges that are around here that we can't see - then we would be attracted to this area and then repelled to this area and then attracted here [pointing to the screen to show the areas where potential static positive and negative charges could be]. This way we will be going in a circle. 
The instructor confirmed that they offered a plausible explanation but asked the students to consider their speed: were they speeding up, slowing down, or moving at a constant rate once they entered the circular motion described above. In response, Student 2 said: "Looks like we are going at a constant speed, though it is difficult to tell." Encouraging the students to increase the charge on their ship once they started going in a circle, the instructor told them to watch what happened.

Responding to the instructor, the students increased their charge to +12 and then sent their ship back into the lines, noting the smaller radius of their ship's circular motion and their increased speed. Due to the change in charge they experienced, the instructor explained that they most likely were in a magnetic field. Finally, the instructor shared with the students that magnetic fields affected moving charges differently than an electric field would affect those same charges. However, this conversation did not explain the nuances or the classical explanation using the right hand rule ${ }^{1}$ which is typically used to determine the direction of a force on a positively charged particle in motion.

The reason for not relaying the information about the right hand rule to the students during the conversation was due, in part, to the design of the Supercharged! game. The objective of the game was to help students develop a qualitative understanding of the dynamics, through experience, of the right hand rule during game play as opposed to the rote memorization of a behavioral rule which they applied but do not necessarily understand. Keeping this inductive method in mind, the instructor asked the students to pay careful attention to their ship's behavior as they passed into a magnetic field [pointed at the screen and told the students that the

\footnotetext{
${ }^{1}$ The right hand rule is a common mnemonic for understanding the direction of force that a charge particle experiences when moving in a magnetic field. For example, if you hold up your right hand with your thumb in the direction of the charge's motion and then imagine that your finger represents the direction of the magnetic field, the direction that your palm faces is the direction of force,
} 
lines represented a magnetic field]. Responding to the instructor's guidance, the students returned to their work and played a few times, changing the magnitude and sign of the charge on their ship. This hands-on guidance and recognition of the need to change the charge magnitudes was reflected in the students' exchange highlighted below:

Student 1: Ok, got it. So what we will need to do is to go to no charge in the field, right?

Student 2: Yes, then we should just go straight [pointing to the screen]. I hope.

Student 1: [Changes their ship's charge to neutral] Cool! Ok, now we just have to time it right to get out!

From this excerpt, the students demonstrated an awareness that like charges repel and unlike charges attract one another as well as understanding that distance had some impact on the speed of their ship. As they progressed through the maze, the students' conversation reflected the growing recognition that they were approaching a magnetic field that they had to navigate through. The students made the assumption based on their previous experiences that they were moving fast enough to navigate right through the magnetic field. However, they quickly noticed that their ship started to undergo circular motion and they could not figure out how to stop that motion. The discussion that follows demonstrates two students attempting to navigate through a magnetic field:

Student 1: Ok, we are going in circles again!

Student 2: I know. What are we? Positive?, Negative?

Student 1: Yes, the screen in red [indicative of a positive charge on their ship]. Ok, so lets go blue [indicative of a negative charge on their ship].

Student 2: All that did was have us spin the opposite direction and go faster. 
Student 1: So when we are positive in spin this way and when we are negative we spin this way [spinning her finger around in the direction of spin of their ship].

Student 2: So what if we have no charge on the ship what happens? We probably just stand still and don't move.

Student 1: Not sure? However, this clearly isn't working and we are only level two so what have got to lose?

Students 1 and 2 shifted their charge to neutral and noticed that their ship went flying off tangentially to the circle that their ship was traveling around. Unfortunately, or fortunately, the students' ship accidently went through the exit before they have a chance to think about what just occurred.

In examining the previous exchange between the students, the particularly interesting aspect was the language that the students used to describe their motion. The students naturally fell into first-person language, talking about themselves as the charge, when attempting to describe their motion to each other and the ship's motion within the game. This shift in language from the third-person perspective to the first-person perspective, about a specific phenomenon, was pedagogically important. In traditional physics classes, instructors ask students to visualize the direction of the charged particles, to "put themselves in the place of the charge" or to "imagine the direction of forces that a test charge will experience in this location". Through playing Supercharged! these students appeared to make the shift in perspective naturally without being told what to do by the instructor, moving toward a first-person perspective.

This perspective shift was not limited to just the game play, but carried over to the written comments in both their post-assessment and their laboratory notebooks. For example, a 
student was asked in a post-assessment which way a charge, that was free to move, was placed between two stationary charges she wrote:

In the game that we played we were the charged a ship and if in this case I take the same view then I would move from the left to the right. The reason for this is because if I assume I am a negative charge placed in the middle of the positive and negative charge then I will move to toward the positive charge.

Similarly, another student in her notebook reflected the benefits that Supercharged! provided in helping her learn about electromagnetic concepts. She recounted how she took on the persona of the ship:

It was very helpful to be the ship. I had never really thought about this topic [electricity and magnetism] before in the way that the game helped me to think about it. In particular, it was helpful for me to be able to look at the ship as the charge I was trying to figure out what direction and how it would move.

One of the major differences between the experimental and control group was the experimental groups' ability to explain how charged particles moved in magnetic fields. This perspective was noted in the two representative excerpts from student notebooks:

Experimental student: From playing the game whenever I was in a magnetic field as a charged particle I went around in a circle. I used to this to navigate around the mazes in the game. The more I was charged the smaller the radius of my circle.

Control Student: I believe that a moving charge would continue through the magnetic field because it only carries a positive or 
negative charge and as a result it will not interact with the magnetic field.

Through examination of the students' interactions during the lab and analyzing the laboratory notebooks, the researchers believed the primary reason for the qualitative nature of the experimental groups was that the experimental groups noted that their first-person experience as a charged ship in a magnetic field influenced their understanding of how magnetic fields effect charged particles. The control group, on the other hand, did not seem to have this first-person experience, but rather relied upon their laboratory activities and the resources in class such as such as simulations and models ( e.g. http://phet.colorado.edu/simulations/index.php?cat=Electricity_Magnets_and_Circuits). The simulations and models allowed the control group students to "visualize" the electric and magnetic fields and how they interacted with one another. However, despite the learning and educative value of these models, they did not permit students to view the problem from a firstperson perspective as was demonstrated by the experimental group playing Supercharged!.

Assertion 2: Game play supported student conversation on "force vs. distance" and the trajectory of moving charges and superposition of forces

The post-assessments and analysis of the laboratory notebooks revealed that students in both the control and experimental groups improved their understanding of basic electrostatics. However, there were some qualitative differences between experimental and control group students. The most striking difference was in the students' descriptions of electric fields and the influence of distance on the forces that electric charges experience. On the post-assessments, typical responses from students in the lab sections who played Supercharged! suggested that 
these students qualitatively understood the inverse relationship between charge and distance. For example, on the post-assessment students were asked to describe the motion of a test charge if it was placed near a set of other charges (see Figure 4). On the post-assessment a student who played Supercharged! wrote:

I picked $\mathrm{C}$ because I believe that it will mostly likely follow a curved path because it will probably feel a force from both sets of charges. However as the charge starts to move toward the right it will feel an increasingly stronger force from the two negative charges and will be pulled that way. Plus given that the force that a charge feels changes dramatically with distance the closer the moving charge gets to the two negative ones as opposed to the single charge.

[Insert Figure 4 about here]

Another student in the experimental group recalled her experience in playing the game when answering the same question:

There will be competing forces. The first force is from the top charge and the other force is from the two charges. As the charge moves toward the right the force from the two charges will start to become stronger and stronger for two reasons. The first reason is that the distance is getting smaller and the closer the charge gets to the positive charges the stronger the force gets. The second reason is that there are two positive charges at the bottom which will overpower the single charge.

Another interesting outcome for the experimental group was that the students again drew upon their game experiences when describing the relationship between force and distance. For example, the students in both groups were given three charges in a diagram on the pre-post 
assessment and asked to describe which direction the test (moveable) charge would move and why (see Figure 5). In the pre-assessments a typical explanation from the experimental group students who played Supercharged! was: "I think the charge will move to the right because it is closer to the one on the right."

\section{[Insert Figure 5 about here]}

However, a fascinating result was that 30 students in the control group (out of 65) and 33 in the experimental (out of 71) who expressed either a misunderstanding or a misconception regarding the movement of charges. In both of these groups typical responses were:

Student 1 (experimental): I think the charge will not move because it is in the middle.

Student 2 (control): I think it will stay in the middle because it is between two equal sized charges.

Student 3 (experimental): I think it will stay in the middle but will bounce and forth between the two charges.

Analyzing the results of the post-assessments revealed that students in the experimental group typically used the in-game experiences to explain their logic answering questions similar to scenarios encountered in Supercharged!. For example, a student in the experimental group noted:

The charge will move toward the closer one because the distance between the charge. I think it will move this way because in level 3 we had to navigate our ship between similar charges and it always moved toward the closer one even if we just a little bit closer. 
While the control group did show improvement in their scores on the post-assessment, their explanations were based as much on their prior knowledge as their laboratory experience. For example, one student from the control group noted that:

I think it will stay in the middle because that is that is where it is most stable. It will probably move but it probably won't move much until it comes to a stop somewhere in the middle. This is because the two charges are the same in size and I remember that the same size charges will put out the same amount of force.

[Insert Figure 6 about here]

It is well documented that students of all ages (e.g. Dede, et al., 1996; Furio \& Guisasola, 1998; Grea \& Moreira, 1997; Viennot, 1994; Viennot \& Rainson, 1992) have great difficulty understanding the phenomenon of electrical field forces superimposing upon one another. Playing the Supercharged! game provided the experimental group students with an opportunity to experience this phenomenon first hand. The impact of this first hand experience was seen in the increased in scores and development of written responses shown on the post-assessment of the experimental group. For example, during game play, students were confronted with multiple charges of varying magnitudes and signs in navigating their ship and to their goal, namely to exit their ship from the level maze. The following exchange demonstrated how two pairs of students, in the experimental group, discussed the problem of multiple charges confronting their ship, actively trying to solve the problem:

Student 1: Ok, there is charge over here and one there and over there [pointing a the screen]. So there are 3 positive and 2 negative and the exit is there. 
Student 2: [in control of the keyboard]. So what if we just go positive that should pull us over there. But...

Student 1: We will get stuck there [pointing to two negative charges].

See even the positives are over there I don't think we will get past the negatives as they are much closer to us at that point [pointing to the screen] and will start to pull us that way more than the positive ones. See but we can get there [again pointing to the screen]. I think then all the forces will just cancel out and then we can coast home.

Student 2: Ok

Another group working on a similar level approached the problem in the same way, but situated themselves in the role of the ship:

Student 3: Ok, we have 6 charges it looks like. [Pointing to them on the screen]. Shouldn't be hard, there is the exit.

Student 4: Ok, so there are forces all over the place. So if we start off as positive then we will be pulled that way [toward a negative charge], and then neutral to pass right on by and once we are probably about here then switch to negative to get those to two pull us their way. Then neutral again.

Student 3: Then looks like some negative and positive switching is needed at that point. As there are lots of forces that will be pulling and pushing in different directions. The exit is there so if we can get and then go neutral and moving in the right direction we should be able to get out.

In both cases, the students were able to place themselves in the position of the ship and imagined the direction of the force by identifying the location of the surrounding charges. In essence, the 
students conducted a qualitative evaluation of the direction of the combined or superimposed force due to the stationary electric charges in the game level. This evaluation was important because as Furio and Guisasola (Furio \& Guisasola, 1998) have pointed out, the ability of students to visualize and understand the superposition of static electric forces can be conceptually challenging, but necessary for students to learn more advanced concepts in electromagnetism.

\section{Assertion 3: Game play did not support student exploration or discussion on static magnetic}

$\underline{\text { fields }}$

Students in the experimental group who played Supercharged! did not develop a conceptual understanding of how magnetic fields impacted stationary charges. In general, the students failed to consider the impact of magnetic fields on stationary charges as a part of their game play. For example, throughout the game most of the students were playing simply to move through either magnetic or electric fields. As such, the students in the experimental group missed many opportunities to evaluate the impact of a magnetic field on a stationary charge because they were focused on maneuvering through the fields to the exit of the maze.

This limitation of the game was clearly evident in the students' post-assessment responses. In the pre- and post-assessments, students were asked to describe what would happen to a stationary charge if it were placed near a bar magnet and then released so it could move. From the experimental group, 55 of the 71 students in the post-assessment said the charge would move, whereas only 3 of the 65 students in the control group said the charge would move. This result is even more striking when comparing the post-assessment results with the pre-assessment 
results. On the pre-assessment, 45 of the students in the experimental group said that the charge would move compared to 38 of the students in the control group.

When comparing the post-assessment written responses, results indicated that students in the experimental group assumed the magnetic field always impacted an electric charge. For example, one student in the experimental group wrote in their journal:

When a charged particle is placed in a magnetic field it will go in circles. If the magnetic field is weak the circles will be smaller. The bigger the charge the smaller the radius of the circle... and if the charge is neutral then the radius of the circle will be large.

Whereas, students in the control group typically wrote the following, demonstrating a greater understanding of how magnetic fields impact charged particles:

Magnetic fields only impact charged particles. If the particle is neutral it will have no effect because there will be no force to move to the charge because its speed is zero. So a magnetic field only affects moving charged particles.

[Insert Figure 7 about here]

Assertion 4: Dislike of playing the game versus traditional instruction

Despite the overall positive learning outcomes for both the control and experimental groups, the students in the control group rated their experience more positively than the students who played Supercharged!. By examining student comments in their notebooks and through a series of questions on the post-survey, the students in the experimental groups seemed to indicate that they did not learn and were not taught about electricity and magnetism. These feelings were illustrated in the following two comments: 
Student 1: The game was fun and all, but do not I feel like I learned anything. I would say on a scale from 1 to 10 , I would have to say 4 . I admit I didn't understand it before and not sure that I understand any better now. I think it would have been better to just hear a lecture on this and some diagrams and graphs would have helped me. I just don't feel that playing a game is the way to learn something as complex as this material.

Student 2: I thought that playing a game would be really helpful. I don't play games that much but I didn't find the experience of playing a game to be very helpful at all. I think I am more confused now than I was before starting the lab. I would change the charge on the ship and then I would move and then I change the charge to something else or make it bigger or smaller but it felt like I was guessing all the time. It would have been helpful to know what we were supposed to be doing rather than just being told, here is a game and by playing the game I will learn about electricity. I am worried that I won't be able to answer the exam questions on this material and feel that the other classes who didn't play the game have a much better understanding of the material than I do.

The two students' comments were not uncommon, with 35 of the 71 students in the experimental group expressing similar sentiments about not "learning" the content for electricity and magnetism. This trend in responses about not feeling that they "learned" the concepts was particularly noteworthy and troublesome since the members of this class were pre-service elementary teachers about to enter the classroom with low perceptions of their abilities and 
knowledge regarding science. These experiences playing the game could very easily have reinforced their negative perceptions of their science knowledge.

In reality, there was a striking contradiction between the students' perceptions about their scientific knowledge of electricity and magnetism and their actual performance on the postassessment including their overall improvement from the pre- to post-assessments. Upon further analysis for potential reasons, we found that many students saw the game as exactly that - a game - not a tool to learn physics concepts. This perspective was reflected in the following students' comments after turning in their final lab report:

Question: Did you feel that through completion of the lab you have a better understanding of the content that was covered in the lab? What did you like and not like about the lab and what recommendations do you have for the instructors in terms of improving the lab?

Answers:

Student 1 (experimental): I felt like I did learn about the content from the game but I think the students who were in the other sections probably learned more because their labs were more hands on. So I don't think I learned as much as others. I liked that the lab was fun and all, but would have liked some more guidance on what we were supposed to be learning from either the lab or the instructors. I would recommend not doing the lab using a game again and have everyone do the same hands-on activities as those are always more helpful. Student 2 (experimental): I liked the idea of playing a game in lab but in terms of learning I don't think a game is the way to do it. I was just thinking about what I will do in my own classroom. I'm not sure I will have my students play video 
games as I am not sure that you learn much from them at all. Though I think I got all the major ideas out of the lab I just think a more hands-on approach is always better and you can use a game as reinforcement or as activity for those more advanced kids once they have finished their work as an enrichment activity. I would make the lab more hands-on, like the other labs in the class have been in the future.

These two excerpts from students suggested two potential issues with using an educational video game in pre-service classrooms. First, many pre-service teachers are on the edge of the "digital native" generation where video and computer games are playing an increasingly important role in students' free time (Prensky, 2004). As such, the pre-service teachers included in this study, may not have had experiences using video games as a learning technology. Rather, most of the pre-service teachers viewed games as entertainment; this may impact their decision to integrate the use of computer games in their future classrooms.

Given the perceptions found in this study points out the importance of highlighting the potential learning benefits of computer games with pre-service teachers. Just as they placed themselves in the position of a charged particle while playing the game, the pre-service teachers need to imagine how their students, fully integrated digital natives, learn from computer games and prepare to meet their needs appropriately. This becomes particularly important because seventy percent of students play computer or video games on a daily basis, while over fifty percent of students in grades three through twelve feel that educational gaming helps them learn (Project Tomorrow, 2008). Second, it is important for teacher educators to be aware that many within the current generation of pre-service teachers may harbor negative perceptions of video games and such perceptions will likely limit their willingness to integrate such tools into their 
future classrooms. Teacher educators need to demonstrate the positive impact of integrating game use into classroom practices in order to address the learning needs of their digital native students. One way to potentially address this is to integrate the approaches taken in both the control and experimental groups; this could be a powerful learning mechanism and could help to mitigate the fears the pre-service teachers expressed regarding not "learning" the content that they felt was necessary.

\section{CONCLUSIONS AND IMPLICATIONS}

Results of this study show that video games can lead to positive learning outcomes, as demonstrated by the increased test scores from pre- to post-assessment for the experimental group students who played Supercharged!. Additionally, this study also suggests that a complementary approach, in which video games and hands-on activities are integrated, with each activity informing the other, could be a very powerful technique for supporting student scientific understanding. One may consider this suggestion as a common sense approach, however, a recent NSF workshop and the recent report on the research agenda for cyber-infrastructure development highlighted the need for significant work to investigate how emerging visualization technologies (like computer games) can be leveraged to support "real life" scientific investigations and vice versa (Computing Research Association, 2006; NSF Task Force on Cyberlearning, 2008).

Further, our findings suggest that video game designers should embed meta-cognitive activities such as reflective opportunities into educational video games to provide scaffolds for students and to reinforce that they are engaged in an educational learning experience. For example, most educational video games that are being used in classrooms have an implicit 
assumption that learning and skill development, such as scientific argumentation practices, will unfold organically. This notion is supported in the literature. Steinkuhler and Duncan (2008) found that game-related forums were rich sites for social knowledge construction where "discursive practices include argument, counter-argument and the use of evidence to warrant one's claims"(p.541) was prevalent and where "the predominant epistemological disposition exhibited in the forum posts was 'evaluative' and therefore appropriate to science" (p. 541). This study supports these notions purported by Steinkuhler and Duncan (2008), but we include the caveat that learning would be supported if appropriate scaffolds are purposively built into video games.

Additionally, we found student learning improved, as evidenced by the pre- to postassessments and lab notebooks; however, we were concerned that the experimental group of students did not find playing Supercharged! to be a learning experience. This perspective could have been for many reasons, such as the relatively unpolished graphical interface of the game compared to what students may experience in game consoles (3D), television (HD), or movies. Another reason could be that the game-based lab was vastly different from their expectations and experiences of a typical lab; this might have resulted in the students being disconnected from the learning aspect of the game, instead judging it solely on "entertainment" value. However, the students' writing and comments suggested that their discomfort with the video game was due to the fact that they did not perceive that a video game could have educational value. This perspective is potentially problematic; if pre-service teachers do not see video games as a learning tool during their teacher education years, then it is unlikely that they will experiment with games or use them as a part of their own practice once they have their own classroom (e.g. Pope, Hare \& Howard, 2002; Russell, Bebell, O’Dwyer, \& O’Connor, 2003). 
From our analysis it appears that students in the experimental group recalled experiences and challenges that were a part of the design of Supercharged!, placing themselves "in" the game. We base this placement of self upon the first-person language that experimental group students used in their descriptions of the ship movement in both post-assessment and laboratory notebooks. Thus, it appeared that through the playing of the first-person Supercharged! game, students were able to place themselves in the role of an electric change and experience how their actions impacted their motion. This approach of "placing oneself" in a visual representation is a typical scientific practice that many scientists use to help them conceptualize or solve a problem (e.g. Ochs, 1990). Hence, our results reinforce the emerging findings that video games (e.g. Annetta, 2008; Kettlehut et al , 2006; Mayo, 2007; Mayo, 2009; McFarlane, Sparrowhawk, \& Heald, 2002; NSF, 2008; Rosas et al, 2003) provide a natural venue to engage students in scientific practices.

These initial findings suggest that the primary affordances of games as instructional tools may be their power for eliciting students' misconceptions (e.g. Brown and Hammer, 2008; diSessa, 2006; diSessa, 2008) and then providing a context for thinking through problems. The challenges that become apparent are that the pre-service teachers do not always perceive that this learning has occurred, nor do they always see the game as a learning experience. While this was often the perception of the students, when analyzing the learning gains from pre- to postassessment, it was clear that the experimental group out performed the control group on most measures. The key becomes helping these pre-service teachers recognize the power of games as a learning tool.

James Gee (2003b) stated: “when kids play videogames they experience a much more powerful form of learning than when they are in the classroom" (webarchive). Gee's statement 
reflects not only about the potential impact that videogames can have on learning, but also the increased interest by educators to develop new and innovative tools to support learning (Gordin \& Pea, 1998; Yair, Mintz, \& Litvak, 2001). This study is unique because it provides evidence regarding how computer video games can be used to support or inhibit student learning of complex physics concepts. It also describes the challenges that students and teachers experience when attempting to use computer video games in a classroom context. In post-assessments, students used game concepts to solve complex Physics problems. In closing, we believe that this study suggests that the active nature of computer game play, the goal-based nature of using the game structures, and the manner in which the students utilized the visual representations within the game context may be beneficial in getting students to think about and understand scientific phenomena, such as electromagnetism, which are often difficult for students to comprehend. 


\section{REFERENCES}

American Association of Physics Teachers (2006). Physics First. College Park, Maryland. Andre, T., \& Ding, P. (1991). Student Misconceptions, Declarative Knowledge, Stimulus Conditions, and Problem-Solving in Basic Electricity. Contemporary Educational Psychology, 16(4), 303-313.

Annetta, L. (2008). Video games in education: Why they should be used and how are they being used? Theory into Practice, 47: 229-239.

Bagno, E., \& Eylon, B. S. (1997). From problem solving to a knowledge structure: An example from the domain of electromagnetism. American Journal of Physics, 65(8), 726-736.

Barab, S. A., Sadler, T. D., Heiselt, C., Hickey, D., \& Zuiker, S. (2007). Relating narrative, inquiry and inscriptions: Supporting consequential play. Journal of Science Education and Technology, 16(1), 59-82.

Barab, S. A., Ingram-Goble, A. \& Warren, S. (2008).Conceptual Playspaces. In R.Ferdig (Ed.) Handbook on Research on Effective Electronic Gaming in Education. New York: IGI Global.

Barnett, M., Keating, T., Barab, S. A., \& Hay, K. E. (2000). Conceptual change through building three-dimensional models. In B. J. Fishman \& S. F. O’Connor (Eds.), Proceedings of the International Conference of the Learning Sciences (pp. 134-142). Hillsdale, NJ: Erlbaum.

Belcher, J. (2003). From the Mind's Eye to 3D Animation: Teaching Electromagnetism with Learning Technology. Last retrieved August 1, 2008 from http://www.wcer.wisc.edu/nise/cl1/ilt/solution/belchej2.htm

Belcher, J., Murray, J., \& Zahn, M. (1999). Force Field: Using Animation in Teaching Electromagnetism. Last retrieved from http://web.mit.edu/user/j/b/jbelcher/www/NSF.html August 12008. 
Blumenfeld, P.C., Soloway, E., Marx, R.W., Krajcik, J.S., Guzdial, M. \& Palincsar, A. (1991). Motivating project-based learning: Sustaining the doing, supporting the learning. Educational Psychologist, 26(3 \& 4), 369-398.

Brown, A. (1992). Design experiments: Theoretical and methodological challenges in creating complex interventions in classroom settings. The Journal of Learning Sciences, 2(2), 141-178.

Brown, D. E. \& Hammer, D. (2008). Conceptual change in physics. In S. Vosniadou (Ed.) International Handbook of Research on Conceptual Change. New York: Routledge. pp. $127-154$.

Bruckman, A. \& Resnick, M. (1995). The MediaMOO Project. Convergence: The International Journal of Research into New Media Technologies, Vol. 1, No. 1, 94-109.

Casperson, J.M. \& Linn, M.C. (2006). Using visualization to teach electrostatics. American Journal of Physics. Vol. 74 (4), Pp. 316-323.

Chambers, S., \& Andre, T. (1995). Are conceptual change approaches to learning science effective for everyone? Gender, Prior subject matter, interest, and learning about electricity. Contemporary Educational Psychology, 20(377-391).

Chi, M. T. H., Feltovich, P. J., \& Glaser, R. (1991). Categorization and representation of physics problems by experts and novices. Cogntive Sciences, 5, 121-152.

Collar, B.D. \& Scott, M.J. (in press). Effectiveness of using a videogame to teach a course in mechanical engineering. Computers and Education.

Collins, A. (1990). Reformulating testing to measure learning and thinking. In N. Frederiksen, R. Glaser, A. Lesgold, \& M. Shafto (Eds.) Diagnostic monitoring of skills and knowledge acquisition (pp. 325-350). Hillsdale, NJ: Lawrence Erlbaum Associates. 
Computing Research Association (2006). Cyber-infrastructure for Education and Learning for the Future: A vision and research agenda.

Cordova, D. I., \& Lepper, M. R. (1996). Intrinsic motivation and the process of learning: Beneficial effects of contextualization, personalization, and choice. Journal of Educational Psychology, 88, 715-730.

Dede, C., Salzman, M., \& Loftin, B. (1996). ScienceSpace: Virtual realities for learning complex and abstract scientific concepts. Paper presented at the Proceedings of IEEE virtual reality annual international symposium, New York.

Dede, C., Salzman, M., Loftin, R. B., \& Sprague, D. (1999). Multisensory immersion as a modeling environment for learning complex scientific concepts. In W. Feurzeig \& N. Roberts (Eds.), Modeling and Simulation in Science and Mathematics Education. New York: Springer Verlag.

Dede, C., Clarke, J., Kettlehut, D., \& Nelson,B. (2005). Students motivation and learning of science in a multi-user environment. Paper presented at the Annual Meeting of the American Educational Research Association, April 2005, Montreal, Quebec, Canada.

de Frietas, S.I. \& Oliver, M. (2006). How can exploratory learning with games and simulations within the curriculum be most effectively evaluated? Computers and Education, 46(3), 249-64.

diSessa. A. (2000). Changing minds. Cambridge: MIT Press.

diSessa, A. (2006). A history of conceptual change research. In R.K. Sawyer (Ed.), The Cambridge Handbook of the Learning Sciences. New York: Cambridge University Press. diSessa, A. (2008). A bird's eye view of the "pieces" vs. "coherence" controversy (from the "pieces"side of the fence). In S. Vosniadou (Ed.) International Handbook of Research on Conceptual Change. New York: Routledge, Pp. 35-60. 
Duit, R. (2006). Bibliography: Students' and teachers' conceptions and science education. Kiel, Germany. IPN. Electronic version downloaded July 22, 2009 from http://www.ipn.unikiel.de/aktuell/stcse/stcse.html.

Dumbleton, T., \& Kirriemuir, J. (2006). Digital games and education. In J. Rutter \& J. Bryce (Eds.), Understanding Digital Games. London: Sage.

Egenfeldt-Nielsen, S. (2006). Overview of the research on the educational use of video games. Digital Kompetase, 1, 184-213.

Engenfeldt-Nielson, S. (2004). Practical barriers in using educational computer games. On the Horizon, 12(1), 18-21.

Erickson, T. (1993). Artificial realities as data visualization environments. In Wexelblat, A. (Ed.), Virtual Reality: Applications and Explorations (pp. 1-22). New York: Academic Press Professional.

Forbus, K. (1997). Using qualitative physics to create articulate educational software. IEEE Expert, May/June, 32-41.

Furio, C., \& Guisasola, J. (1998). Difficulties in learning the concept of electric field. Science Education, 82(4), 511-526.

Games-to-Teach Team. (2003). Design principles of next-generation digital gaming for education. Educational Technology, 43(5), 17-33.

Gee, J.P. (2003). What videogames have to teach us about learning and literacy. New York: Palgrave Macmillan.

Gee, J.P. (2003b). High Score Education: Games, not school, are teaching kids to think. Wired. Accessed online May 2009 from http://www.wired.com/wired /archive/11.05/view_pr.html

Ginn, I.S. \& Watters, J.J. (1995). An analysis of scientific understandings of Pre-service elementary teacher education students. Journal of Research in Science Teaching. 
Vol. 32(2), Pp. 205-222.

Glaser, B.G. \& Strauss, A.L. (1967). The discovery of grounded theory. Chicago, IL: Aldine Publishing.

Gordin, D. N., \& Pea, R. D. (1998). Prospects for scientific visualization as an educational technology. The Journal of the Learning Sciences, 4(3), 249-279.

Grea, I. M., \& Moreira, M. A. (1997). The kinds of mental representations - models, propositions, and images - used by college physics students regarding the concept of field. International Journal of Science Education, 19(6), 711-724.

Gros, B. (2003). The impact of digital games in education. First Monday, 8(7).

Guruswamy,C., Somers, M.D., \& Hussey, R.G. (1997). Students' understanding of the transfer of charge between conductors. Physics Education, Vol. 32, Pp. 91.

Hewitt, P.G. (2002). Conceptual physics with practicing physics workbook.. NY: Benjamin Cummings.

Hostetter, O. (2003). Video Games - The necessity of incorporating video games as part of constructivist learning. Retrieved from http://www.gameresearch.com/art_games_constructivist.asp

Kebritchi, M., Hirumi, A., Bai, H. (2008). The effects of modern math games on learners' achievement and math course motivation in a public high school setting. UCF Research Brief. Retrieved July 22, 2009 from http://www.dimensionsm.com/docs/UCFResearch_Brief_June_202008.pdf .

Kettlehut, D, Dede, C., Clarke, J. \& Nelson, B. (2006). A multi-user virtual environment for building higher order inquiry skills in science. Paper presented at the American Educational Research Association International Conference. San Francisco, CA.

Kirriemuir, J., \& McFarlane, A. (2004). Literature review in games and learning UK: Futurelab. 
Lincoln, Y.S. \& Guba, E.G. (1985). Naturalistic Inquiry. Newbury Park, CA: Sage.

Linn, M.C., and Eylon, B. Science Education: Integrating Views of Learning and Instruction. Alexander, P.A., and Winne, P.H. (Eds.), Handbook of Educational Psychology, 2nd Edition, Lawrence Erlbaum Associates, 2006.

MacDonald, K., \& Hannafin, R. (2003). Using web-based computer games to meet the demands of today's high stakes testing: A mixed methods inquiry. Journal of Research on Technology Education 35(4), 459-472.

Mayo, M.J. (2007). Games for science and engineering education. Communications of the ACM, 50 (7) pp. 30-35.

Mayo, M.J. (2009). Video games: A route to large-scale STEM education? Science,323, pp. 7982.

McClean, Phillip, Bernhardt Saini-Eidukat, Donald Schwert, Brian Slator, Alan White (2001). Virtual Worlds in Large Enrollment Biology and Geology Classes Significantly Improve Authentic Learning. In: Selected Papers from the 12th International Conference on College Teaching and Learning (ICCTL-01), Jack A. Chambers, Editor). Jacksonville, FL: Center for the Advancement of Teaching and Learning. April 17-21, pp. 111-118.

McFarlane, A., Sparrowhawk, A., \& Heald, Y. (2002). Report on the educational use of games: An exploration by TEEM of the contribution which games can make to the education process. Cambridge.

McDermott, L.C., Shaffer, P.S., \& Constantinou, C.P. (2000). Preparing teachers to teach physics and physical science by inquiry. Physics Education, 35, Pp. 411-416.

Miller, C.S., Lehman, J.F., \& Koedinger, K.R. (1999). Goals and learning in microworlds. Cognitive Science, 23(3), Pp. 305-336. 
NSF Task Force on Cyber-learning (2008). Fostering Learning in the Networked World: Learning Opportunity and Challege, a 21st century agenda for the National Science Foundation. Arlington, VA: National Science Foundation.

Oblinger, D.G. (2006). Games and Learning: Digital games have potential to bring play back to learning experience. Educause Quarterly 3.

Ochs, W. (1990). The importance of phase space dimension in the intermittency analysis of multi hadron production. Physics Letters, 247 (1), 101.

Pope, M., Hare, D., \& Howard, E. (2002). Technology integration: Closing the gap between what pre-service teachers are taught to do and what they can do. Journal of Technology and Teacher Education, 10 (2), Pp. 191-203.

Prensky, M. (2004). The motivation of gameplay. On the Horizon, 10(1).

Prensky, M. (2001). Digital Game Based Learning. New York: McGraw Hill.

Project Tomorrow (2008). Leadership in the $21^{\text {st }}$ Century: The New Visionary Administrator. Irvine, CA: Project Tomorrow. Retrieved June 8, 2009 from http://www.blackboard.com/Solutions-by-Market/K-12/Learn-for-K12/LeadershipViews/Education-in-the-21st-Century.aspx

Psotka, J. (1996). Immersive training systems: Virtual reality and education and training. Instructional Science 23 (5-6), 405-423.

Redish, E. F. (1993). The implications of cognitive studies for teaching physics. American Journal of Physics, 62(9), 796-803.

Rosas, R., Nussbaum, M., Cumsille, P., Marianov, V., Correa, M., Flores, P., et al. (2003). Beyond nintendo: Design and assessment of educational video games for first and second grade students. Computers \& Education, 40, 71-94. 
Russell, M., Bebell, D., O'Dwyer, L., \& O'Connor, K. (2003). Examining teacher technology use: Implications for pre-service and in-service teacher preparation. Journal of Teacher Education, V. 54: 297.

Schoon, K. \& Boone, W.J. (1998). Self-efficacy and alternative conceptions of science of pre-service elementary teachers. Science Education, 82(5), Pp. 553-568.

Shaffer, D.W. , Squire, K., Halveson, R.P. and Gee, J.P. (2004). Video games and the future of learning. Phi Delta Kappan.

Squire, K. (2008). Video game-based learning: An emerging paradigm for instruction. Performance Improvement Quarterly, V. 21, No. 7, Pp. 7-36.

Squire, K. (2006). From content to context: Videogames as designed experience. Educational Researcher, 35(8), 19-29.

Squire, K. (2004). Replaying history. Unpublished Dissertation, Indiana University Bloomington.

Squire, K. (2003). Video games in education [Electronic Version]. International Journal of Intelligent Games and Simulations. Retrieved September 5, 2006 from http://www.scit.wly.ac.uk/ cm1822/ijkurt.pdf.

Squire, K., Barnett, M., Grant, J.M., Higginbotham, T. (2003). Electromagnetism Supercharged! Learning physics with digital simulation games. Paper presented at the annual meeting of the International Conference of Learning Sciences. San Diego, California.

Steinkuhler, C. \& Duncan, S. (2008). Scientific habits of mind. Journal of Science Education and Technology.17:530-543. 
Van Eck, R. (2006). Presentation at Educause Learning Initiative Annual Meeting. Paper presented at the Educause Learning Initiative Annual Meeting from http://www.educause.edu/upload/presentations/EL1061/FS04/Van\%Eck.swf.

Viennot, L. (1994). Students' understanding of superposition of electric fields. American Journal of Physics, 62, 1026-1032.

Viennot, L., \& Rainson, S. (1992). Students' reasoning about the superposition of electric fields. International Journal of Science Education, 14(4), 475-487.

White, B. Y., \& Frederiksen, J. R. (1998). Inquiry, Modeling, and metacognition: making science accessible to all students. Cognition and Instruction, 16(1), 3-118.

Willamson, B., \& Facer, K. (2004). More than just a 'game': The implications for schools of children's computer game communities. Education, Communication, and Information, $4(2 / 3)$

Yair, Y., Mintz, R., \& Litvak, S. (2001). 3D-Virtual reality in science education: An implication for astronomy teaching. Journal of Computers in Mathematics and Science Teaching, $20(3), 293-305$. 
Figures

Figure 1: Creating a dipole. Image courtesy of John Belcher

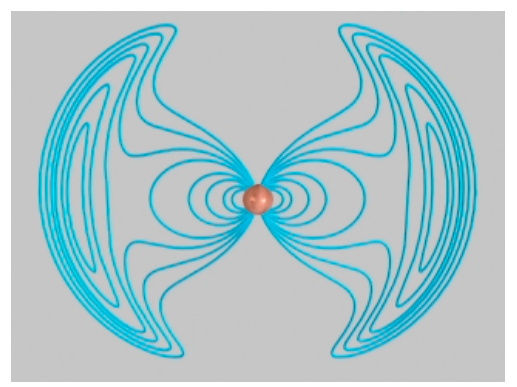

Figure 2: Magnetic Field filled screen in Supercharged!

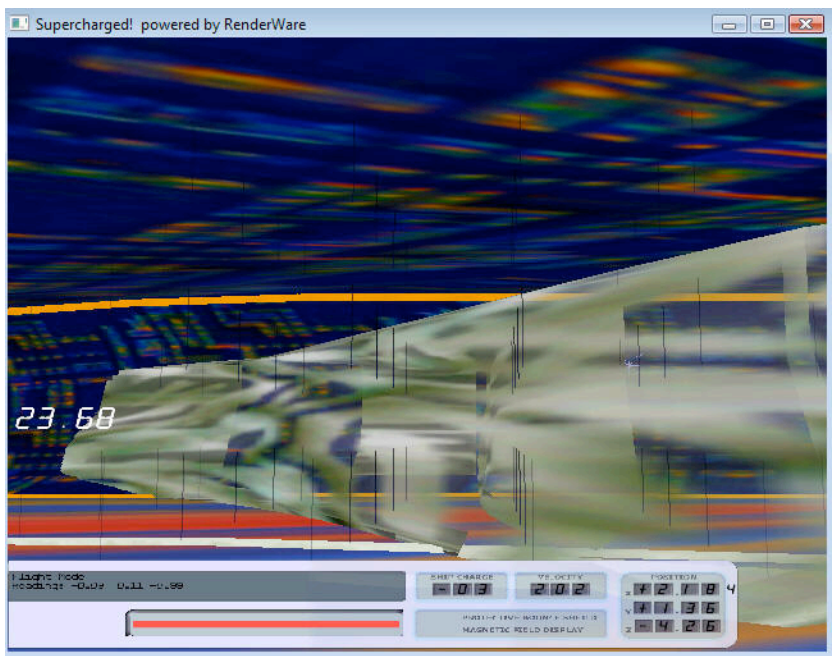

Figure 3: Screenshot of Level 2 - Maze with magnetic field

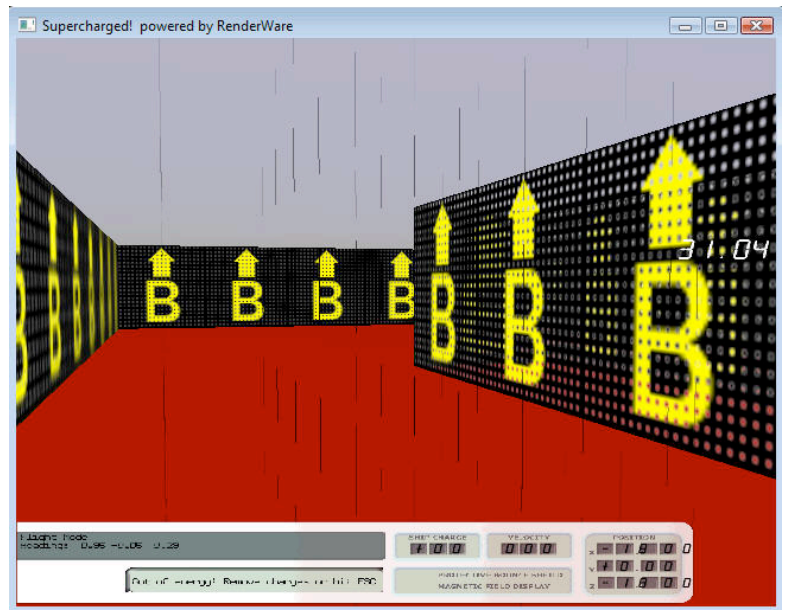


Figure 4: Direction of Charged Particle

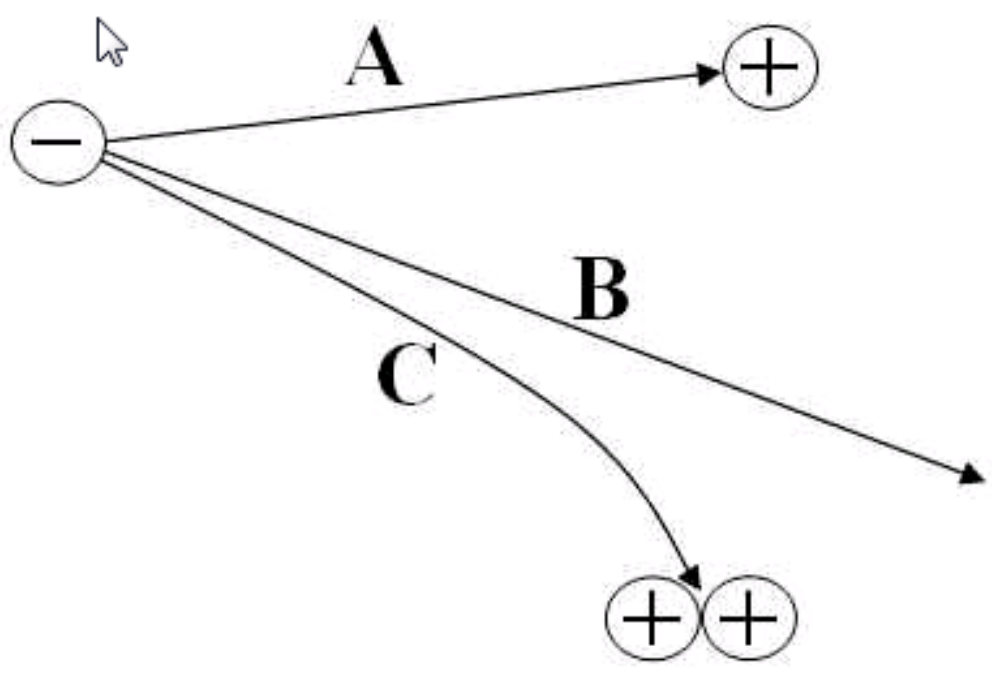

Figure 5: Image on pre-post assessment for which way the charge will move
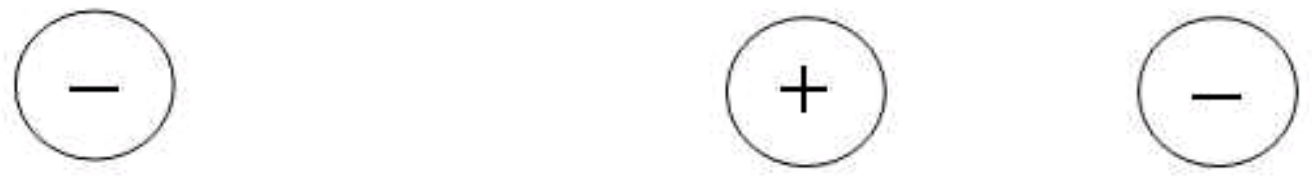

Figure 6: Level 3 Screenshot - Negative charge with barriers

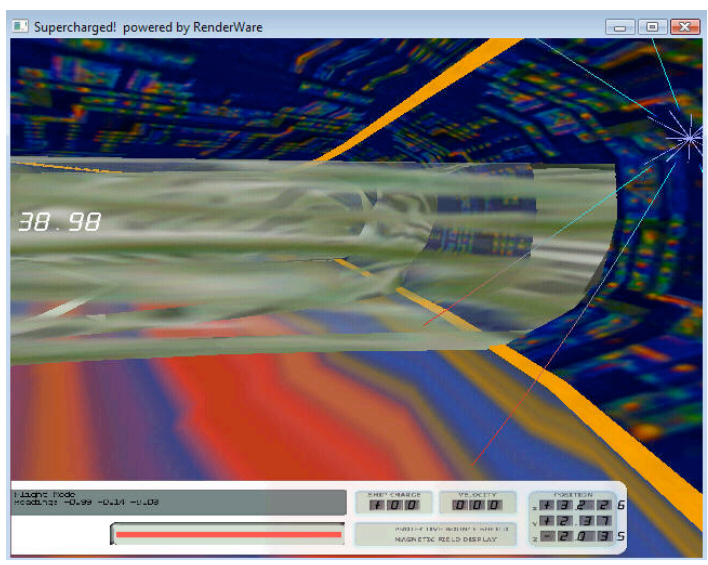


Running Head: Video Games, Physics, and Pre-service Elementary Teachers - NARST 2010 Philadelphia, PA 50

Figure 7: Level 4 Screenshot - Magnetic Field with a charge

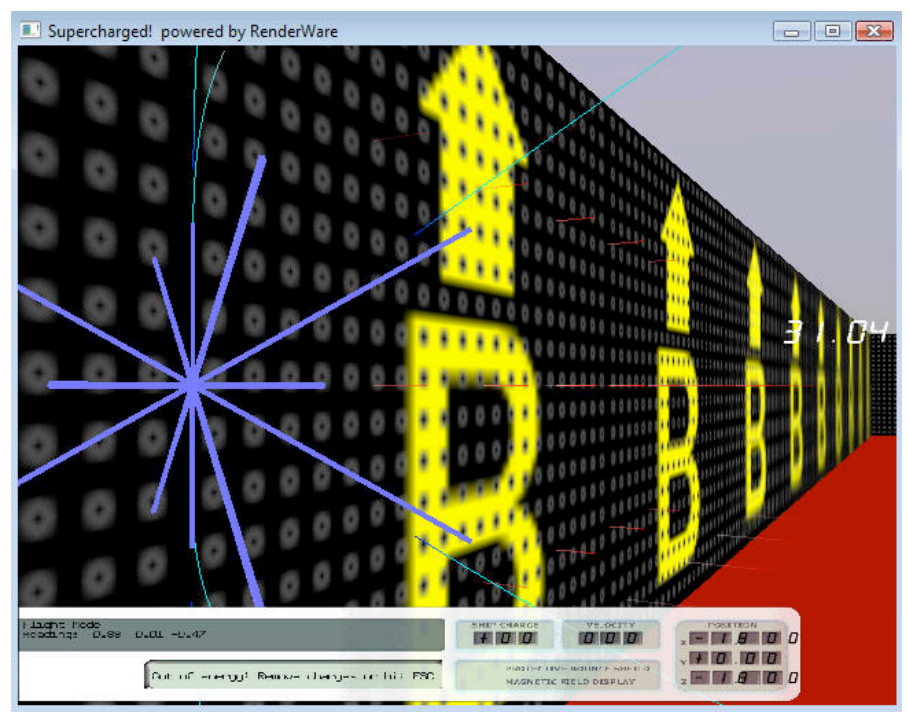

